\title{
What Motivates Men's Involvement in Gender- Based Violence Prevention? Latent Class Profiles and Correlates in an International Sample of Men
}

\author{
Erin A. Casey
}

University of Washington Tacoma, ercasey@uw.edu

Richard M. Tolman

Juliana Carlson

Christopher T. Allen

Heather L. Storer

Follow this and additional works at: https://digitalcommons.tacoma.uw.edu/socialwork_pub

Part of the Social Work Commons

\section{Recommended Citation}

Casey, Erin A.; Tolman, Richard M.; Carlson, Juliana; Allen, Christopher T.; and Storer, Heather L., "What Motivates Men's Involvement in Gender-Based Violence Prevention? Latent Class Profiles and Correlates in an International Sample of Men" (2016). Social Work \& Criminal Justice Publications. 434.

https://digitalcommons.tacoma.uw.edu/socialwork_pub/434 


\section{What motivates men's involvement in gender-based violence prevention?: Latent class profiles and correlates in an international sample of men}

Corresponding Author:

Erin A. Casey, MSW, PhD

University of Washington, Tacoma

1900 Commerce Box 358425

Tacoma, WA 98402

253.692.4524

ercasey@u.washington.edu

Richard M. Tolman, MSW, PhD

University of Michigan

School of Social Work

1080 S. University Avenue

Ann Arbor, MI 48109-1106

734-764-5333

rtolman@umich.edu

Juliana Carlson, AM, PhD

University of Kansas

School of Social Welfare

104 Twente Hall

Lawrence, KS 66044

(785) 864-9026

jmcarlson@ku.edu

Christopher T. Allen, PhD

University of Massachusetts Lowell

113 Wilder Street, Suite 300

Lowell, MA 01854

(978) 934-3964

christopher_allen@uml.edu

Heather Storer, MSW, PhD

Tulane University

School of Social Work

127 Elk Place

New Orleans, LA 70112

hstorer@tulane.edu

Acknowledgements: The authors would like to extend sincere gratitude to Juan Carlos Areán, Rus Funk, Jonathan Grove, and Oswaldo Montoya, who generously donated consultation regarding the content and translation of the survey used in this research. We are also grateful to the participants in this survey, and to the Mobilizing Men for Violence Prevention Global Advisory Board. 


\begin{abstract}
Data from an international sample of 392 men who had attended gender-based violence (GBV) prevention events were used to examine motivations for involvement in GBV prevention work. Participants responded to an online survey (available in English, French and Spanish). The most commonly reported reasons for involvement included concern for related social justice issues $(87 \%)$; exposure to the issue of violence through work (70\%); hearing a moving story about domestic or sexual violence (59\%); and disclosure of abuse from someone close to the participant (55\%). Using a latent class analysis, we identified four profiles of men's motivations: Low Personal Connection (22\%), Empathetic Connection (26\%), Violence Exposed Connection (23\%) and High Personal and Empathetic Connection (29\%). Participants classified into these profiles did not differ in length of movement involvement but some differences on key ally variables and by global region did emerge. Implications for engagement strategies and future research are discussed.
\end{abstract}

Keywords: Gender-based violence, violence against women, allyship, engaging men, violence prevention. 


\section{INTRODUCTION}

The proactive engagement of men and boys as contributors to the prevention of genderbased violence (GBV) is becoming an increasingly common component of violence prevention efforts globally. Concomitantly, scholars and activists have given attention to effective strategies for reaching out to male-identified individuals as well as to catalysts in men's lives that motivate them to seek or accept anti-violence involvement. These outreach and engagement efforts are often framed in terms of "ally" development (Casey and Smith 2010; Edwards, 2006), in recognition that engaging men and boys in violence prevention is, in part, a process of mobilizing a group that is socially privileged by their gender identity to work against one of the deleterious outcomes of the existence of that very privilege - gender-related violence. As such, prompting men's anti-violence participation can be a complex enterprise, complete with the simultaneous and somewhat competing components of helping men to feel welcome and invited into working to end violence, while also supporting men in viewing GBV as an issue that is relevant to themselves, and as one that is inextricably tied to gender inequity and male privilege.

To date the evidence regarding the strategies, approaches, or experiences that most effectively initiate men's involvement in GBV prevention events or work is relatively young. Emerging findings regarding men's anti-violence engagement are largely descriptive and come from small qualitative samples. Further, research has not yet examined the degree to which specific reasons for men's initial anti-violence involvement are associated with successful longterm engagement, or with attitudes, beliefs and behaviors that are consistent with gender justicerelated goals. The purpose of this study is therefore to add to the knowledge base regarding effective men's engagement strategies by examining patterns of motivations for anti-violence 
involvement in a global sample of men who have attended violence-prevention events, and the subsequent associations between those patterns and men's ally-related attitudes and behaviors.

\section{Conceptualizing Men's Development as Gender-Based Violence Prevention Allies}

Although literature specific to men's initiation into anti-violence participation is relatively sparse, conceptual models from related ally movements, such as anti-racism, hetereosexism, and ableism are instructive and relevant. Existing models of ally development largely take a developmental approach, suggesting that entrée into activist and social justice endeavors may be based on a constellation of experiences, learning opportunities, reflection and meaning-making that occur over time (e.g. Broido 2000; Edwards 2006). For example, based on a series of qualitative interviews with college-age racial social justice allies in the U.S., Reason, Miller and Scales (2005) proposed a model of initiation into an ally identity that includes an emerging awareness of whiteness and privilege, coupled with tangible racism-related learning opportunities, exposure to racially diverse communities, and concrete invitations to take part in anti-racist activism. Collectively, these experiences help to coalesce an awareness of white privilege and a structural analysis of racism that foster a deeper commitment to anti-racism work. Elements of this model have been surfaced in qualitative studies of heterosexual allies of lesbian, gay, bisexual and transgender communities in the U.S. (Asta and Vacha-Haase 2013), and general social justice ally identification (Munin and Speight 2010) in the U.S.

Evidence suggests that a developmental approach is similarly relevant to GBV prevention involvement among male-identified individuals. For example, building on earlier frameworks outlining social justice ally development, Casey and Smith (2010) propose a model of men's pathways into anti-violence work based on qualitative interviews with 27 adult men in the U.S. who had recently initiated anti-GBV involvement. Men reported exposure to initial "sensitizing 
experiences" such as hearing disclosures of violence from women close to them, being exposed to violence-related learning opportunities, and experiencing their own exposure to violence or identity-based marginalization. Men noted that these initial experiences were then reinforced by concrete opportunities or invitations to take tangible action against GBV in some way, and by particular meaning-making experiences. Motivating meaning-making included, for example, an emotional and personal connection to the issue of violence against women, a sense of connection with a community of individuals working to end violence, and/or an emerging understanding of violence as something structurally embedded and that compels immediate action.

Similar models of gender justice awareness among men also incorporate elements of stages of change models (e.g. Prochaska et al. 2002) - models that assume a continuum of "statuses" over time relative to men's awareness, willingness, and ability to act as an ally to women. For example, in a qualitative study with 62 Nicaraguan young men participating in gender equity and sexual health education programs, Torres and colleagues (2012) identify a process of gender equity awareness they term "expanding your mind." Comprised of four statuses ranging from a pre-awareness "apprentice" status to a final, feminist identity, men's movement across these statuses were influenced by exposure to gender-related learning opportunities, being part of groups of gender and sexual identity-equitable men, and personal reflection. This model echoes conceptual frameworks regarding men's anti-violence involvement that similarly adopt a "stages of change" approach (Edwards 2006; Funk 2006). For example, Edwards (2006) argues that prospective social justice allies, including male anti-violence allies, occupy different statuses over time ranging from self-interested allyship on behalf of particular women they care about to a social justice-informed allyship enacted in solidarity with and accountability to women and other marginalized identities. 
Across these frameworks, initial catalysts for men's gender equity involvement are appropriately subsumed in overall, chronologically-organized modeling of ally development over time. It may also be that men's initial experiences or reasons for seeking or accepting opportunities for anti-violence involvement are differentially related to the nature of their subsequent engagement in GBV prevention. It may be important to isolate and specifically examine this initial "pre-engagement" stage, and the correlates of particular pathways into GBV prevention work for men. A more specific focus on understanding initial engagement may be instructive for strategizing the effective and judicious engagement of larger circles of men.

\section{Conceptualizing Catalysts for Men's Anti-Violence Involvement}

Evidence is beginning to emerge about the factors that encourage or motivate men's initial involvement in preventing GBV. A number of studies, for example, identify disclosures of abuse by close family members or friends, hearing stories from survivors, or personally experiencing violence as important factors that initiated their role as anti-violence allies in the U.S. (Casey and Smith 2010; Piccigallo et al. 2012) and Canada (Coulter 2008). Opportunities to learn about violence against women, through presentations, workshops, and survivor testimonials or speak outs, have similarly been identified as promising involvement catalysts in Nicaragua (Torres et al. 2012), Ecuador (Goicolea et al. 2012) and the U.S. (Casey and Smith 2010). Individualized invitations to attend or contribute to anti-violence events, and encouragement from respected role models, family members, or peers constitute another common entry point. For example, in a study of a gender-transformative HIV prevention program for men in South Africa, Kalichman and colleagues (2008) found that leveraging peer social networks to recruit participants was an effective way to enlist new participation among men. Similarly, a qualitative study of 29 organizations around the world that include men's engagement in their violence 
prevention work found that programs in many countries employ an "ambassador" approach to outreach (Carlson et al. 2015). This approach involves recruiting individuals trusted by their community to reach out to other men in ways that are tailored to local context and culture.

Men also become involved as allies by identifying GBV as a social justice issue that is structurally embedded, and as an issue that intersects with other causes they prioritize. These may be issues they identify with because of their own marginalization due to poverty, race, sexual orientation, or other social locators, or they may be other social issues that they have allied across privilege to support (Casey and Smith 2010). Adoption of this structural analysis distinguished anti-violence "activists" from "non-activists" in one study of Ecuadoran young men (Goicolea et al. 2012). Promoting this type of structural analysis has also been identified as a core principle of men's engagement efforts globally (Peacock and Barker 2014). Across these initial strategies for influencing men's willingness to be exposed to GBV prevention, however, it remains unclear whether particular strategies are more effective at garnering men's initial help, and/or whether these initial kinds of motivations combine in particularly compelling ways to propel men into longer-term anti-violence work.

\section{Summary and Aims}

In summary, qualitative and conceptual work related to men's entrée into GBV prevention suggests the utility of a developmental model and has begun to document some potential motivations for involvement. These motivations have not yet been replicated outside of qualitative work or examined for relevance across geographic regions that have myriad contextspecific structures of privilege and marginalization. Additionally, empirical work has not yet addressed the question of how men's initial motivations for anti-violence involvement might be associated with different longer-term outcomes and longevity as an ally. It may also be that 
unique initial involvement motivations combine into different pathways to GBV prevention events or male allyship. Understanding such pathways could inform diverse strategies for fostering men's engagement, and for examining whether particular pathways are more associated with men's effectiveness and longevity as GBV prevention activists.

To address these questions, we used latent class analysis to identify profiles of men's motivations for anti-violence engagement in an international sample of men who have attended GBV prevention events. Specifically, the aims of the paper were to 1) test the utility and prevalence of qualitatively derived catalysts of men's involvement in a geographically diverse global sample, 2) determine if unique profiles of motivations can be identified among male participants, 3) examine whether identified profiles of involvement motivation are differentially associated with ally-related attitudes and behavioral intentions, and 4) examine regional variation in motivation profiles.

\section{METHODS}

\section{Procedures}

Data were collected anonymously between the Fall of 2013 and Spring of 2014 via an online survey, translated from English into French and Spanish, with back-translation conducted for accuracy. Prior to dissemination, the French and Spanish versions of the survey were examined by native speakers in each of these languages for accuracy and revisions were made to increase items' readability, and cross-language consistency.

Participants were recruited though email invitations and postings on relevant violence and prevention-related email list-serves around the world. Invitation emails were also sent to violence prevention and intervention programs around the world located through web-based searches. Programs with publicly available contact information were contacted two times each 
with requests to forward the survey information and link to potentially interested and eligible participants. These invitations also contained survey and participation information in English, French, and Spanish. Finally, a small number of participants (19) were recruited through two organizations that used the survey to evaluate prevention events. Participants were not offered incentives. The Institutional Review Board at the University of Washington approved all procedures.

\section{Sample}

A total of 744 individuals consented to the survey and completed eligibility screening items, with 471 continuing into the body of the survey. Most of the attrition was due to ineligibility (not identifying as male, being under 18 , or not attending a prevention event), although some respondents entered the survey but did not complete any items and some were eliminated as probable duplicative entries. To be included in analyses described in this paper, participants must have responded to questions regarding their initial motivations for attending a violence prevention event or getting involved in GBV prevention work. The final sample for this analysis included 392 participants, ranging in age from 18 to "over 65 " $(\mathrm{m}=41.41, \mathrm{sd}=13.56)$. Regionally, approximately $9 \%$ of participants were from Africa, $6 \%$ from Asia, $11 \%$ from Europe, 17\% from Latin America and the Caribbean, 56\% from North America, and 1\% from Oceania. Seventy-seven percent of participants took the survey in English, 21\% in Spanish and $2 \%$ in French. Length of anti-violence involvement among participants ranged from less than one year to nearly 22 years $(m=7.58, s d=6.50)$. Approximately $63 \%$ of participants were employed at a violence prevention-related organization at the time of survey completion, $22 \%$ had volunteered with an organization, and $15 \%$ of participants were not formally employed nor volunteering at a relevant organization. 


\section{Measures}

Latent class indicators: Motivations for anti-violence involvement. Initial motivations for anti-violence involvement were assessed through a 15-item index; items are provided in Table 2. Items were developed from earlier qualitative work examining precipitants of men's antiviolence involvement (Casey \& Smith, 2010) and through review and consultation with community-based practitioners and the project's advisory board. Participants were instructed to "think back to some of the factors that influenced" them to become involved in anti-violence work or events, and could select as many reasons for involvement as applied in a yes/no format. Participants who left all motivation items blank were not included in analyses and those who skipped some but not all motivation items were coded as missing on those items. Participants could also select an "other" option if they felt reasons for their own involvement were not reflected in the list. An open-ended space then allowed participants who checked "other" to further explain their additional reasons. A total of 109 participants selected "other" among their responses and provided additional information. An initial content analysis of open-ended responses suggested that participants largely used this space to elaborate on motivation items they had endorsed rather than providing qualitatively new motivations for involvement. Therefore no additional "motivations" items were created for inclusion in the latent class analysis based on open-ended responses.

Ally-related variables. We measured several constructs designed to characterize participants' degree of involvement in anti-violence work, and their attitudes and beliefs about salient gender and violence-related constructs. Participants were asked to estimate how many years of anti-violence involvement they logged, as well as how many hours per week they intend to devote to anti-violence work in the future. For each of these, participants provided a number. 
We used two subscales from the Male Gender Equality Scale (Allen 2010) to assess support for gender equality and recognition of male privilege, respectively. Sample items for the support for gender equality subscale include "I value women's and men's intellect equally," and "It bothers me that some men use power to have sexual control over women." Items in the recognition of male privilege scale include "I have changed some of my beliefs and behaviors in order to become less sexist," and "Sometimes, I feel angry about how women are treated in our society." Response options spanned a three-point scale inclusive of -1 "disagree," 0 "neither agree nor disagree," and 1 "agree." Overall mean scores for each scale were computed. Cronbach's alpha for gender equity and male privilege items for the participants included in these analyses were .74 and .79 , respectively.

Items assessing bystander self-efficacy and bystander willingness were created for this study, informed by existing scales such as the Bystander Efficacy Scale (Banyard et al. 2007). Eleven identical bystander actions were used in each scale, inclusive of both proactive (e.g. talking to a younger man or relative about respect in relationships) and reactive (e.g. telling a man who was being disrespectful to women to stop) behaviors that men could take in their daily lives to prevent violence. Self-efficacy items began with the stem "how confident are you that you could... [take each of the listed actions] with response options ranging from 1 "not at all confident" to 7 "very confident." Similarly, willingness items started with the stem "In the next 6 months, how willing are you to..." with response options ranging from 1 "not at all willing" to 7 "very willing." Overall mean scores for each scale were computed. Cronbach's alphas for the self-efficacy and willingness items were .79 and .90 , respectively.

Network support for gender-based violence prevention. To measure social network support for participants' involvement in preventing GBV, we asked them to rate how many of 
the men among their friends and family, respectively "would be willing to participate in an event/events like the one you attended." Response options included the following; 1 "none," 2 "a few," 3 "about half," 4 "most," and 5 "all."

Finally, respondents were asked about potential reasons for sustaining their $G B V$ prevention involvement over time. Seventeen items were developed for the project in a process similar to the motivations for initial involvement described above. Items were derived from previous qualitative work by the team (Carlson et al., 2015; Casey and Smith, 2010), and were influenced by conceptual models of ally development proposed by Edwards (2006). Items were also reviewed by and developed in consultation with current prevention practitioners. Sustaining options ranged from more personal reasons, (such as "I have a skill I can contribute," "It helps improve my relationships with women," and "I like the attention I get when I do this work"), to more social justice-related incentives ("I want to be a part of ending oppression of all kinds," and "I would like to expand ideas about masculinity and what it means to be a man"). Items capturing potentially more paternalistic motivations ("I feel that women need protection," and "I want to be a voice for women, since women often cannot use their own voices") were also included. Respondents were asked to rate each item on a scale that ranged from 1 "strongly disagree" to 7 "strongly agree."

Demographics. Participants were asked to indicate their age in years; response options extended to 65 , and were capped at "over 65 " in an attempt to accommodate an unwieldy dropdown menu for this survey item. We used the United Nations (UN) list of countries from which respondents could indicate their country of residence. UN-derived regions were then used to group countries into larger geographic regions (UN 2014).

\section{Analysis Approach}


We used latent class analysis (LCA), a mixture modeling approach, to identify patterns of motivations for anti-violence involvement. Mixture modeling empirically identifies homogeneous subgroups of individuals within larger samples without imposing a priori assumptions about the nature of those subgroups (Lanza and Collins 2008). LCA is therefore a "person-centered" approach that identifies types, or "classes" of individuals within a population who share similar profiles across a range of indicator variables. This approach is advantageous because it allows for the detection of how specific motivators for anti-violence involvement may combine in unique patterns across groups of men.

We used LCA with Mplus 7.0 software to identify classes of individuals based on men's endorsement of the 15 item "reasons for involvement" index. These indicators are listed in Table 2. Models were estimated iteratively with an increasing number of classes specified at each step. The optimal solution was identified using criteria recommended by Muthén and Muthén (2000). These included classification quality (entropy), likelihood ratio tests, fit to the data as reflected by Bayesian and Akaike Information Criteria values (BIC and AIC), and classes’ size, interpretability, and theoretical coherence. Once an optimal solution was identified, the model was re-run using increasing numbers of random starts to ensure the stability of the solution. Following the LCA, we conducted post-hoc Wald chi-square tests of equality across groups to examine whether and how class membership was differentially associated with age, length of anti-violence involvement, gender attitude and bystander-related variables, and participants' motivations for sustaining involvement. This method of post-hoc comparisons on noncategorical variables is built into Mplus as an optimal approach, as it incorporates posterior probabilities of class membership, and thus models error associated with class membership uncertainty (Muthén and Muthén, 2010). Comparisons across classes by global region, a 
categorical variable, were conducted in SPSS 19.0 using chi square analysis. It should be noted that although some observed frequencies within cells fell below $n=5$ in this analysis, no expected frequencies did so, maintaining the appropriateness of this approach.

\section{RESULTS}

\section{Motivations for Anti-Violence Involvement}

Proportions of the overall sample endorsing each precipitant of attending a GBV event can be found in the far right column of Table 2 . The most commonly reported reasons included concern for related social justice issues $(87 \%)$ and exposure to the issue of violence through work $(70 \%)$. Hearing a moving story about domestic or sexual violence (59\%), and hearing a disclosure of abuse from someone close to the participant (55\%) were also among the more commonly selected motivations. The least commonly endorsed items included past use of violence (24\%) and being accused of harassment or violence (8\%). On average, respondents endorsed 6.26 reasons $(\mathrm{sd}=3.30)$, with only 25 respondents $(6 \%)$ selecting just one catalyst for involvement in prevention events or work.

\section{Latent Class Analyses}

Fit indices for the two, three, four, and five class LCA models are provided in Table 1.We selected the 4-class model as the best solution, because it had substantially smaller BIC and AIC values than the three-class solution, solid classification probabilities, and conceptually clear group characteristics. It also had a statistically significant Lo-Mendell-Rubin (LMR) adjusted likelihood ratio test that became nonsignificant with the five-class model (indicating worse fit compared to the four-class model). The five-class solution also demonstrated deteriorating BIC and plateauing AIC values. As a whole, these indicators provide strong support for the 4-class solution as the optimal model. It should be noted that entropy scores across all 
models were acceptable, though modest, suggesting that additional indicators emerging from future research may be helpful in fully distinguishing motivation profiles.

\section{Pathways to Involvement Groups}

Scores on the reasons for involvement indicators for the four latent class groups are displayed in Table 2. The groups were of roughly similar size. It bears noting that while LCA can identify groups that differ significantly from each other on rates of endorsement of some indicator variables, the classes are derived from the overall pattern of responses across all indicators simultaneously. Classes may therefore have significant differences across some, but not all indicators. Since it is the totality of the patterns that distinguishes classes from one another, variable by variable difference testing is not typically done for LCA indicators, nor was it done here. Below, we describe each of the four pathways groups in more detail.

The first group consisted of men with the lowest level of endorsement of nearly all involvement indicators; accordingly, we termed this group the "Low Personal Connection" to violence group. Comprised of $22 \%$ of the sample, men in this class appear to have found their way to GBV prevention events primarily through their work, or involvement in other social justice issues. Although their endorsement of the social justice indicator was still slightly lower than the other classes, men in this group had the second highest proportion of men exposed to the issue of violence through their work. Further, the Low Personal Connection Group cited work and social justice concerns as the most common reasons for involvement. None of the men in this group reported past use of or being accused of violence, and very few were exposed to disclosures of or victimization by violence directly.

Similar to the Low Personal Connection group, the second class had relatively low personal exposure to violence or past use of violence. Named the "Empathetic Connection" 
group, this class was characterized by the endorsement of motivators such as hearing disclosures of violence from people close to them, hearing moving stories about violence, and seeking or getting information about violence through presentations, lectures or the internet at rates that were higher than the overall sample. Consisting of roughly $26 \%$ of the sample, the Empathetic Connection group's pattern across involvement indicators suggests that their personal and empathetic motivation for initiating anti-violence engagement may have been an emotional connection initiated by hearing the stories of others, including loved ones.

The final two groups were similar to each other in that both had high rates of personal exposure to or victimization by violence, as well as relatively higher rates of reporting the past use of violence. What distinguishes the final groups from each other is their differential endorsement of the other involvement indicators. The first of these groups, the "Violence Exposed Connection" group, consisted of $23 \%$ of the sample. This group reported nearly universal witnessing or experiencing of violence, and $42 \%$ of the men in this group reported being targeted for violence because of some aspect of their identity. About a quarter of the group reported using violence themselves at some point in the past. Across all other indicators except for concern for social justice, this group fell below the overall sample average; their endorsement of concern for social justice as a motivator for involvement was roughly equal to the sample average. Men in this group, therefore, may have been motivated to address GBV primarily because of their personal experiences with violence.

The fourth group was termed the "High Personal and Empathetic Connection" group and comprised $29 \%$ of the total sample. Like the third group, men in this class had very high levels of personal exposure to, victimization by, and past use of violence. Unlike the Violence Exposed group, however, the High Personal and Empathetic Connection group had the highest rates of 
endorsement of all involvement indicators relative to all other classes. Thus, in addition their own experiences of violence, men in this group were exposed to or sought out learning opportunities and the stories of others, and were encouraged by respected others to get involved at high rates. Notably, $81 \%$ of the group report improved relationships with women as a motivator. While violence exposure may have been an early motivator for this group, these men appeared to be highly active in seeking out additional information about violence, making connections in the community and connecting GBV to other social justice issues.

\section{Motivation for Involvement Groups: Associations with Ally Variables.}

Table 3 displays differences across motivation groups on ally-related variables. The four classes did not significantly differ in their length of anti-violence involvement or in the number of hours per week that they intend to devote to the work in the future. Men in the Low Personal Connection group were slightly older, on average, than men in the Violence Exposed Connection group, but no other significant age differences existed between groups.

All motivations groups reported high endorsement of gender equity and bystander-related variables, indicating that on the whole, men in the sample hold attitudes and beliefs consistent with gender justice efforts. Additionally, these groups did not differ on their scores for attitudes toward gender equity. Groups did differ, however on the remaining ally-related variables. Members of the High Personal and Empathetic Connection class had a significantly higher mean score on the awareness of male privilege scale than either the Low Personal Connection or Empathetic Connection groups, and a higher bystander self-efficacy score than all other groups. Men in the Empathetic Connection group also reported higher bystander self-efficacy than the Low Personal Connection group. Similarly, men in the Empathetic Connection and High Personal and Empathetic Connection groups reported greater levels of bystander willingness than 
the Low Personal Connection group, with the High Personal and Empathetic Connection group's scores also exceeding the Violence Exposed group. Finally, members of the High Personal and Empathetic Connection group reported a higher proportion of male friends who would be supportive of GBV prevention efforts than all other groups, and a greater proportion of male family members who would support these efforts than the Low Personal Connection and Violence Exposed Connection groups. Men in the Empathic group also reported a higher percentage of men in their friendship networks who would support GBV prevention efforts than men in the Violence Exposed Connection group.

\section{Sustaining Anti-Violence Involvement Over Time}

We also compared classes on their reasons for sustaining anti-violence involvement over time, and fewer significant differences emerged between groups on these variables (these results are therefore not tabled). For example, groups reported relatively similar levels of endorsement of sustaining factors such as feeling they are making a difference, wanting to expand ideas about masculinity, impacting issues of oppression more generally, feeling connected to others doing GBV prevention work, or feeling they have a particular skill that is needed. When differences did emerge, they were related to two domains. First, men in the Empathetic Connection and High Personal and Empathetic Connection group were more likely to report wanting to be a voice for women $(m=4.54$ and 4.43 , respectively) than were men in the Low Personal Connection $(\mathrm{m}=3.75)$ or than the Violence Exposed Connection $(\mathrm{m}=3.34)$ groups (Wald $\chi^{2}=14.97(3), \mathrm{p}$ <.001). Members of the High Personal and Empathetic Connection group also endorsed the belief that women need protection $(\mathrm{m}=4.96)$ as a sustaining factor in their involvement at rates higher than the Low Personal Connection $(\mathrm{m}=4.13)$ and Violence Exposed Connection $(\mathrm{m}=3.81)$ groups (Wald $\chi^{2}=11.55(3), \mathrm{p}<.01$ ). Second, significant differences were found on sustaining 
variables that were related to the nature of group members' behaviors in and relationships with others. The High Personal and Empathetic Connection group endorsed the item "I am trying to change my own behavior," $(\mathrm{m}=5.35)$ at rates that were higher than the Low Personal Connection $(\mathrm{m}=4.21)$ and Empathetic Connection $(\mathrm{m}=4.61)$ groups (Wald $\left.\chi^{2}=9.99(3), \mathrm{p}<.05\right)$. The High Personal and Empathetic Connection group and Empathic groups also reported higher endorsement of the belief that anti-violence involvement improves their relationships $(\mathrm{m}=6.13$ and 5.90, respectively) than the Low Personal Connection group ( $\mathrm{m}=5.01)$ (Wald $\chi^{2}=14.26$ (3), $\mathrm{p}<.01)$.

\section{Motivation for Involvement Groups: Regional Differences}

Regions of the world were significantly differentially represented across motivation for involvement groups, (displayed in table 4). Note that men from Australia and New Zealand were not included in this analysis because of their low representation in the sample (1\%). Although there were no regional differences in the proportion of men in the Empathetic group, all other groups differed significantly by region. Specifically, Africa, Asia, and Latin America had higher representations of the High Personal and Empathetic Connection group relative to Europe and North America, while Europe and North America had higher representation of the Low Personal Connection group compared to Asia and Africa. More men from Latin America and the Caribbean were members of the Low Personal Connection group than were men in Asia. Finally, European men had higher representation in the Violence Exposed Connection group than African and North American participants.

\section{DISCUSSION}

Relative to the first aim of the study, to examine the prevalence of precipitants of men's involvement in a geographically diverse global sample, we found that a social justice 
commitment (and relatedly, exposure to GBV prevention through employment in an associated field) is the most often endorsed reason for involvement across three of the four classes. Leveraging men's pre-existing concern for issues such as oppression and marginalization, and helping them to make connections between the forms of social injustice with which they are familiar and the issue of GBV is a strategy reinforced by these findings. Another highly endorsed entrée motivation was hearing disclosures and stories about abuse, and this may be a particularly strategic approach for those men for whom social justice is more of a growth issue. Many of the men in this sample likely deepened an empathetic and perhaps personal connection with the issue of GBV through their exposure to the compelling stories of survivors. Some caution is warranted here; as Piccigallo and colleagues suggest (2012), the strategy of having individuals who have experience with violence, often women, sharing their stories to generate men's involvement, necessarily places some burden on victims. Secondarily, holding women's stories up as survivors or victims of GBV could perhaps inadvertently reinforce notions of men as protectors of women, and women as potential victims in need of protection, ideas that do not fundamentally challenge gender inequity. Parallel research examining males becoming stakeholders in sexual assault prevention has shown that including examples of male victimization can be effective at fostering empathy for victims and sparking a connection to the issue of violence among men (e.g., Piccigallo et al., 2012). Taken together, this suggests the importance of leveraging survivor stories carefully, including the voices of people with whom men identify, and helping them to link their personal experiences to the reality of violence in their own communities.

Overall, and similar to past research, most participants had multiple precipitants of antiviolence involvement. On a general level, the moderate to strong endorsement of most involvement motivations suggests preliminary support for the relevance of this index across 
geographic regions. Given that only a few men in the sample listed only one reason for their involvement, it may be that men with fewer precipitants are never successfully engaged. Although we could not capture temporality in this project, the idea that men need several involvement motivations reinforces the notion of a developmental process of men's engagement in violence prevention work, and that involvement motivations likely unfolded over time and were mutually reinforcing. Clearly, early exposure to or experience of violence during a man's childhood would precede all other precipitants, but subsequent experiences such as someone encouraging involvement or hearing a disclosure could become powerful catalysts for violence prevention involvement. Similar to previous research, our sample draws largely from successfully engaged men; research is needed with non-engaged or unsuccessfully engaged men to better understand the factors most associated with a sustained willingness to incorporate antiviolence actions into one's life.

In fulfillment of our second study aim, we identified four conceptually meaningful patterns of men's reasons for getting involved in violence prevention. The emergence of these classes suggests the need to look at men's motivations for involvement in concert rather than isolation and to think about how they extend or reinforce one another. There was also heterogeneity in the paths that men in this sample took to get to these anti-violence events. Likewise, intentional outreach and engagement needs similar tailoring to line up to that heterogeneity. For example, some men in this sample (the Empathetic Connection group) had no personal exposure to violence; engagement for them necessitated hearing moving stories and likely making emotional connections between others' experiences and the implications of those experiences for the men's own lives, families, and communities. On the other hand, many men in this sample had been exposed to or used violence; for these men, making the connection between 
their own victimization and the issue of GBV was likely a critical component of their process of engagement. Programmatic efforts could tailor their strategies by considering the diversity of latent motivations within their likely participants. For example, a program could survey their target population of men about their experiences and about possible 'hooks,' or issues about which they care the most. Early individual conversations with potential allies may also be important, to tailor invitations and involvement to the motivations and developmental "stage" of allyship each person occupies. Finally, the heterogeneity of involvement paths reported here support the notion of diverse and sequenced programming that builds on initial or early motivations (perhaps violence exposure or hearing disclosures or stories) and that over time, supports men to make broader linkages to social justice and gender equity.

The role of early exposure to violence in the Violence Exposure Connection and High Personal and Empathetic Connection groups is important to examine further. Violence exposure can create risk for future perpetration (Roberts et al. 2010), but clearly it can also be a point of connection for anti-violence activism. Anti-violence allyship patterns are complex in that men can simultaneously occupy a space of privilege within the realm of gender justice efforts, and be directly impacted by violence victimization or exposure, as well as by marginalization based on other aspects of their social location. This raises two points. First, men's engagement efforts must both acknowledge and help men make connections between their own intersectional experiences of privilege and marginalization, and link these to the perpetuation of gender inequity. Second, the differences between the Violence Exposed and the High Personal and Empathetic Connection groups (both groups with high rates of personal experiences of violence) suggest that for men previously exposed to violence, multiple subsequent learning and reflection opportunities may be an important part of resiliency and anti-violence commitment. This is 
evidenced by the fact that the High Personal and Empathic Connection group, who endorsed involvement motivations such as the attending learning events, hearing form survivors, and receiving encouragement to attend anti-violence events, also reported the highest levels of gender equitable and positive bystander attitudes.

Several findings emerged relative to our third aim, which was to examine whether profiles of involvement motivation are differentially associated with ally-related attitudes and behavioral intentions. It bears reiterating that somewhat of a ceiling effect for ally variables did appear, as all were relatively strongly endorsed across the sample as a whole. Models of ally development (Broido and Reason 2005) suggest that allyship is predicated on the internalization of an understanding of privilege and this data seems to suggest that most men in this sample indeed are reporting attitudes and beliefs consistent with this understanding.

At the same time, different patterns of motivations for involvement are associated with some variability in gender and ally-related variables. Participants in the Empathic Connection and High Personal and Empathetic Connection groups have higher awareness of male privilege, more bystander confidence and willingness, and are surrounded by more gender-equitable men in social networks. What these two groups share is the higher endorsement of multiple involvement motivations - especially information-seeking and exposure to disclosures. This finding again highlights the importance of multiple opportunities to learn, think about, discuss, and understand GBV, and to create linkages between disparate experiences or involvement opportunities. Ultimately, perhaps, both an emotional connection to and an intellectual understanding of GBV (or other social justice issues) is maximally desirable.

Interestingly, while evidencing the highest levels of gender equitable attitudes, the High Personal and Empathetic Connection men were also more likely to endorse protecting women 
and being their voice, stances which have been interpreted in some contexts as inappropriately paternalistic in GBV prevention work. For the purposes of this discussion, we offer up a variety of ways of understanding this and invite the field to consider these findings within the conceptual and methodological context of this study. First, the finding again highlights the complexity of men's relationships to GBV prevention. Other global studies of men's violence-related attitudes have found that men simultaneously hold gender equitable and inequitable or protective attitudes at the same time, and that these may be in flux (e.g. Levtov et al. 2014). For some men in this group, there may be some cognitive dissonance between the felt need to protect women and notions of gender equality. Another interpretation is perhaps some of the men in the High Personal and Empathetic Connection group are in families or contexts where the women really could have benefitted from greater protection, and speaking for them is a form of activism that the women in those contexts see as needed. Finally, this finding could also be a related to the linguistic translation or understanding of the phrasing in different contexts that does not contain overt paternalistic meanings. Perhaps protecting women and speaking for them could have different connotations for men in different places, similar to other ways men's ideas about gender equality are historically, politically, and materially bound within specific geographic and cultural contexts (Levtov et al. 2014). In a context where women are relatively safe to express beliefs or where social policies support gender equity, then "protection" may be understood differently.

The fourth and final aim of the study was to examine regional variation in motivation profiles. Regional differences did emerge, although it is likely that some differences are due to constraints of sampling. For example, while virtually no Low Personal Connection men were from Africa or Asia, there were few participants from Africa or Asia in our sample. Europe and 
North America had lower representations of High Personal and Empathetic Connection men than Africa and Asia, suggesting that perhaps men in Africa and Asia have more comprehensive opportunities for exposure to GBV prevention events or work. These regional differences emphasize the importance of cross-regional fertilization in conceptualizing effective approaches to engaging men. Replication of results in other regions with similar measures would help to validate whether this was an issue of sampling or is an accurate regional difference.

\section{Limitations}

Limitations include the over-representation of participants from North America, and the restriction of the survey to English, Spanish or French speakers, and those with reliable Internet and computer access. Additionally, although significant pre-testing of the survey took place in all three languages, context-specific meanings of ideas within the survey are likely to differ, and impact the way participants responded. It was also not possible to capture data on multiple axes of men's identities across all of the multiple geographic regions included in the study, given the nuanced, myriad, and context-specific approaches to characterizing ethnicity, nationality, religion, class, and caste in each location. This study therefore constitutes a broad look at potentially relevant anti-violence motivations which should be critically examined in future research in more specific contexts, through the lens of men's intersectional identities in those regions. Further theoretical development on how local and regional masculinities impact men's anti-violence involvement will depend on these more context specific studies. Research capturing the experiences of men who have not yet attended prevention events, who are very newly involved, or who have had engagement opportunities but have not elected to become involved is also needed as our sample had higher representations of men successfully engaged, employed or volunteering in prevention. Finally, the cross-sectional nature of the data prohibits 
definitive conclusions about temporal ordering of involvement motivations and ally-related attitudes or behaviors.

\section{Conclusion}

This study offers a preliminary exploration of how men are motivated to become allies in ending GBV and provides a conceptualization of motivations for initial engagement that can be examined in future research. Subsequent studies can expand upon this cross-sectional survey method to more fully illuminate the temporal trajectories of ally development. If the global movement to involve men in GBV continues to grow, empirical investigation of how men enter into and sustain that work may move from the margins to a more central focus of GBV prevention research. Given the global nature of the movement, we hope subsequent work will continue to be informed by both regional and cross-regional studies. Theory development in this arena draws upon and can inform understanding of other social justice efforts that involve ally engagement and development. While we are not suggesting that engaging men is in itself an end goal of GBV prevention efforts, understanding more about how men become engaged and deepen their involvement in gender equitable ways can inform strategies for enhancing that involvement. Of course, research on whether and under what conditions such involvement leads to actual reductions in GBV is also critically important. We hope our study can prove useful in both informing this movement and in providing a base for future research. 


\section{References}

Allen, Christopher. T. "Engaging men in violence prevention: Empirically examining theoretical barriers and catalysts.” Doctoral Dissertation University of South Carolina, 2010.

Asta, Elizabeth L., and Tammi Vacha-Haase. "Heterosexual Ally Development in Counseling Psychologists Experiences, Training, and Advocacy.” The Counseling Psychologist 41, no. 4 (2013): 493-529.

Banyard, Victoria, Mary Moynihan, and Elizabeth Plante. "Sexual Violence Prevention Through Bystander Education: An Experimental Evaluation. Journal of Community Psychology, 35 (2007): 463-481.

Barker, Gary, Ricardo, Christine, and Nascimento, Marcos. "Engaging men and boys in changing gender-based inequity in health: Evidence from programme interventions." World Health Organization. 2007. http://www.who.int/gender/documents/Engaging_men_boys.pdf

Broido, Ellen M. "The development of social justice allies during college: A phenomenological investigation." Journal of College Student Development 41, no. 1 (2000): 3-18.

Carlson, Juliana, Erin Casey, Jeffrey L. Edleson, Richard M. Tolman, Tova B. Walsh, and Ericka Kimball. "Strategies to Engage Men and Boys in Violence Prevention A Global Organizational Perspective." Violence Against Women (2015): 1077801215594888.

Casey, Erin, and Tyler Smith. "“How Can I Not?": Men's Pathways to Involvement in AntiViolence Against Women Work." Violence Against Women 16, no. 8 (2010): 953-973.

Coulter, Rebecca Priegert. "Boys doing good: Young men and gender equity." Educational Review 55, no. 2 (2003): 135-145.

Edwards, Keith E. "Aspiring social justice ally identity development: A conceptual model." Journal of Student Affairs Research and Practice 43, no. 4 (2006): 1235-1256.

Funk, Rus Ervin. Reaching men: Strategies for preventing sexist attitudes, behaviors, and violence. Indianapolis, IN: JIST Life, 2006.

Goicolea, Isabel, Ann Öhman, Mariano Salazar Torres, Ione Morras, and Kerstin Edin. "Condemning violence without rejecting sexism? Exploring how young men understand intimate partner violence in Ecuador." Global Health Action 5 (2012).

Kalichman, Seth C., Leickness C. Simbayi, Allanise Cloete, Chauncey Cherry, Anna Strebel, Moira O. Kalichman, Tammy Shefer et al. "HIV/AIDS risk reduction and domestic violence prevention intervention for South African men." International Journal of Men's Health 7, no. 3 (2008). 255-273. 
Lanza, Stephanie T., and Linda M. Collins. "A new SAS procedure for latent transition analysis: transitions in dating and sexual risk behavior." Developmental Psychology 44, no. 2 (2008): 446-456. doi:10.1037=0012- 1649.44.2.446

Levtov, Ruti Galia, Gary Barker, Manuel Contreras-Urbina, Brian Heilman, and Ravi Verma. "Pathways to Gender-equitable Men Findings from the International Men and Gender Equality Survey in Eight Countries." Men and Masculinities 17 no. 5 (2014): 467-501.

Munin, Art, and Suzette L. Speight. "Factors influencing the ally development of college students." Equity \& Excellence in Education 43, no. 2 (2010): 249-264.

Muthén, Bengt, and Linda K. Muthén. "Integrating person- centered and variable- centered analyses: Growth mixture modeling with latent trajectory classes." Alcoholism: Clinical and Experimental Research 24, no. 6 (2000): 882-891.

Muthén Bengt, and Linda K. Muthén "Equality test of means across latent classes using Wald Chi-Square based on draws from posterior probabilities." (2010) http://www.statmodel.com/download/meantest2.pdf.

Peacock, Dean, and Gary Barker. "Working with Men and Boys to Prevent Gender-based Violence Principles, Lessons Learned, and Ways Forward." Men and Masculinities 17, no. 5 (2014): 578-599.

Piccigallo, Jacqueline R., Terry G. Lilley, and Susan L. Miller. “"It's Cool to Care about Sexual Violence" Men's Experiences with Sexual Assault Prevention." Men and Masculinities 15 , no. 5 (2012): 507-525.

Prochaska, James. O., Redding, Colleen. A., \& Evers, Kerry. E. "The Transtheoretical Model and stages of change," In Health Behavior and Health Education: Theory, Research and Practice edited in Karen Glanz, Barbara K. Rimer, \& F. M. Lewis, 99-120 (3 ${ }^{\text {rd }}$ ed., pp.). San Francisco, CA: Jossey-Bass, 2002..

Reason, Robert Dean, Elizabeth A. Roosa Millar, and Tara C. Scales. "Toward a model of racial justice ally development." Journal of College Student Development 46, no. 5 (2005): 530546.

Roberts, Andrea L., Stephen E. Gilman, Garrett Fitzmaurice, Michele R. Decker, and Karestan C. Koenen. "Witness of intimate partner violence in childhood and perpetration of intimate partner violence in adulthood." Epidemiology (Cambridge, Mass.) 21, no. 6 (2010): 809.

Torres, Virgilio Mariano Salazar, Isabel Goicolea, Kerstin Edin, and Ann Öhman. "'Expanding your mind': the process of constructing gender-equitable masculinities in young Nicaraguan men participating in reproductive health or gender training programs." Global Health Action 5 (2012). 
United Nations "Composition of macro geographical (continental) regions, geographical subregions, and selected economic and other groupings." Last updated October 31, 2013. https://unstats.un.org/unsd/methods/m49/m49regin.htm 
Table 1. Latent class analysis: Fit indicators for models of different class sizes

\begin{tabular}{llllllll}
\hline & & & & & Classification \\
Model & BIC $_{\text {ssa }}$ & AIC & Entropy & Class Sizes & Quality & LMR \\
\hline 2-class & 6185 & 6062 & .77 & 234,158 & $.95, .91$ & $* * *$ \\
3-class & 6108 & 5921 & .79 & $179,119,94$ & $.91, .94, .87$ & $* * *$ \\
4-class & 6086 & 5836 & .77 & $116,100,89,87$ & $.88, .87, .89, .89$ & $*$ \\
5-class & 6144 & 5830 & .75 & $93,84,99,50,66$ & $.86, .88, .85, .80, .76$ & NS \\
\hline$* \mathrm{p}<.05, * * \mathrm{p}<.01, * * * \mathrm{p}<.001$ & & &
\end{tabular}


Table 2 - Motivations for involvement groups: Four class solution summary

\begin{tabular}{|c|c|c|c|c|c|}
\hline $\begin{array}{l}\text { LCA Indicator s: Reasons } \\
\text { for getting involved in anti- } \\
\text { violence against women } \\
\text { work: }\end{array}$ & $\begin{array}{c}\text { Class 1 } \\
\text { Low } \\
\text { Personal } \\
\text { Connection } \\
(\mathbf{n}=87)\end{array}$ & $\begin{array}{c}\text { Class 2 } \\
\text { Empathetic } \\
\text { Connection } \\
(\mathbf{n}=\mathbf{1 0 0})\end{array}$ & $\begin{array}{c}\text { Class } 3 \\
\text { Violence } \\
\text { Exposure } \\
\text { Connection } \\
(\mathbf{n}=\mathbf{8 9})\end{array}$ & $\begin{array}{l}\text { Class } 4 \text { High } \\
\text { Personal } \\
\text { and } \\
\text { Empathetic } \\
\text { Connection } \\
(n=116)\end{array}$ & $\begin{array}{c}\text { Full } \\
\text { sample }\end{array}$ \\
\hline $\begin{array}{l}\text { Concerned about related social } \\
\text { justice issues, like } \\
\text { oppression... }\end{array}$ & $71 \%$ & $88 \%$ & $88 \%$ & $98 \%$ & $87 \%$ \\
\hline $\begin{array}{l}\text { Exposed to issue through my } \\
\text { work }\end{array}$ & $69 \%$ & $62 \%$ & $65 \%$ & $85 \%$ & $70 \%$ \\
\hline $\begin{array}{l}\text { Heard a moving story about } \\
\text { violence }\end{array}$ & $24 \%$ & $79 \%$ & $38 \%$ & $93 \%$ & $59 \%$ \\
\hline Someone close to me disclosed & $18 \%$ & $68 \%$ & $42 \%$ & $90 \%$ & $55 \%$ \\
\hline $\begin{array}{l}\text { Someone close to me } \\
\text { encouraged me to get involved }\end{array}$ & $36 \%$ & $61 \%$ & $41 \%$ & $73 \%$ & $53 \%$ \\
\hline $\begin{array}{l}\text { Witnessed/experienced } \\
\text { violence in own life }\end{array}$ & $8 \%$ & $19 \%$ & $86 \%$ & $97 \%$ & $52 \%$ \\
\hline Went to a presentation & $12 \%$ & $89 \%$ & $8 \%$ & $96 \%$ & $52 \%$ \\
\hline $\begin{array}{l}\text { Wanted to meet people in the } \\
\text { community like me }\end{array}$ & $17 \%$ & $47 \%$ & $42 \%$ & $74 \%$ & $45 \%$ \\
\hline $\begin{array}{l}\text { Wanted to improve } \\
\text { relationships with women }\end{array}$ & $7 \%$ & $44 \%$ & $41 \%$ & $81 \%$ & $44 \%$ \\
\hline $\begin{array}{l}\text { Saw violence in own house as } \\
\text { a child }\end{array}$ & $6 \%$ & $19 \%$ & $55 \%$ & $82 \%$ & $40 \%$ \\
\hline Saw something on the internet & $5 \%$ & $47 \%$ & $10 \%$ & $72 \%$ & $33 \%$ \\
\hline $\begin{array}{l}\text { Sermon or lecture by someone } \\
\text { I respect }\end{array}$ & $7 \%$ & $50 \%$ & $10 \%$ & $67 \%$ & $33 \%$ \\
\hline $\begin{array}{l}\text { I've been targeted because of } \\
\text { identity }\end{array}$ & $7 \%$ & $2 \%$ & $42 \%$ & $64 \%$ & $27 \%$ \\
\hline Used violence in the past & $0 \%$ & $9 \%$ & $26 \%$ & $64 \%$ & $24 \%$ \\
\hline $\begin{array}{l}\text { Was accused of harassment or } \\
\text { violence }\end{array}$ & $0 \%$ & $2 \%$ & $10 \%$ & $24 \%$ & $8 \%$ \\
\hline
\end{tabular}


Table 3: Class differences across ally-related variables

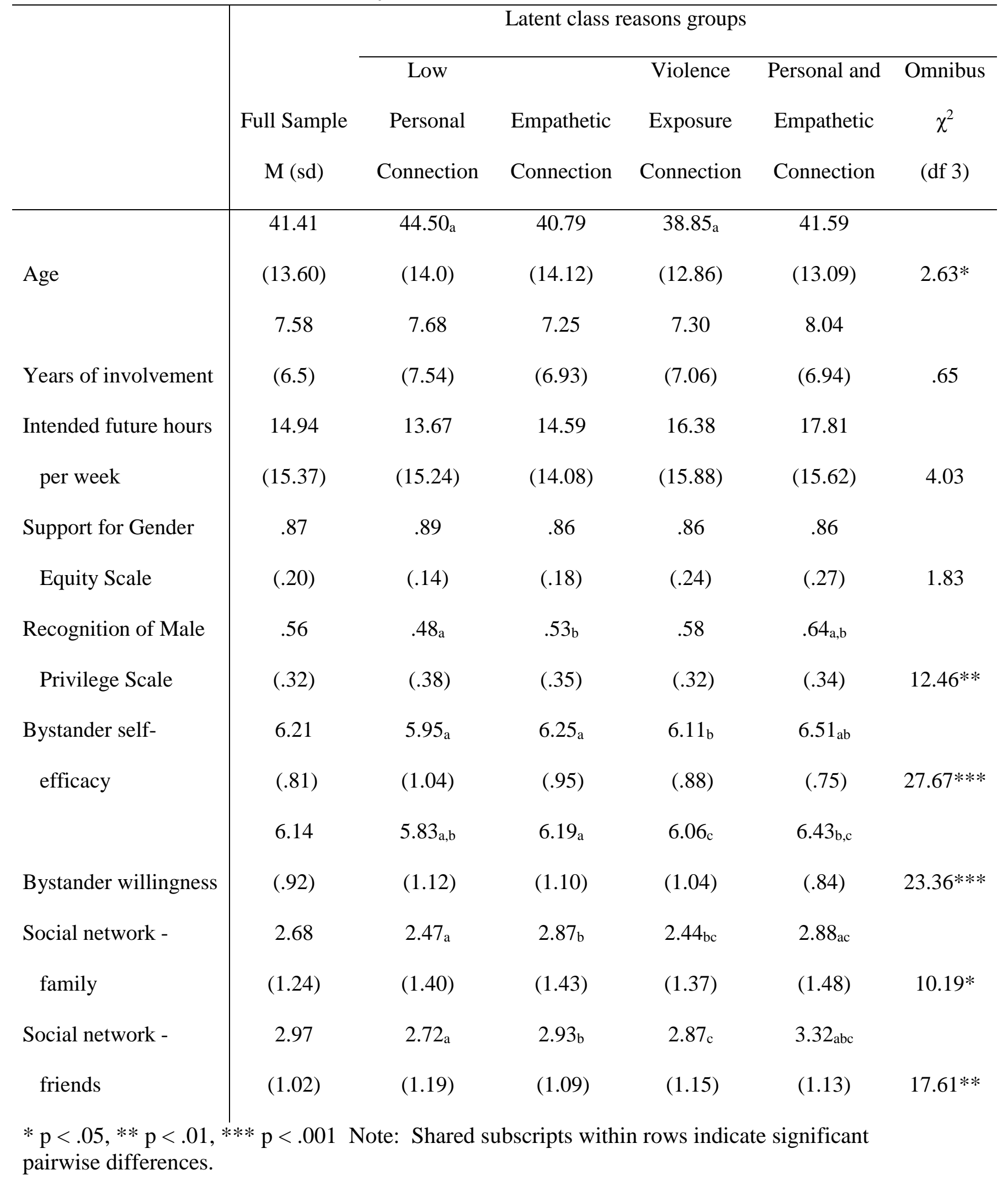


Table 4. Motivation for involvement classes by global region

\begin{tabular}{c|ccccc}
\hline \multirow{2}{*}{ Motivation Class } & \multicolumn{5}{|c}{ Region } \\
\cline { 2 - 6 } & \multicolumn{5}{c}{ Latin } \\
& & & & America/ & North \\
& Africa & Asia & Europe & Caribbean & America \\
\hline \multirow{2}{*}{ Low Personal Connection } & 2 a,b & 0 c,d,e & $11_{\mathrm{a}, \mathrm{c}}$ & $13 \mathrm{~d}$ & $54_{\mathrm{b}, \mathrm{e}}$ \\
& $(6.5 \%)$ & $(0 \%)$ & $(27.5 \%)$ & $(22.0 \%)$ & $(26.9 \%)$ \\
Empathetic Connection & $(25.8 \%)$ & $(33.3 \%)$ & $(25.0 \%)$ & $(18.6 \%)$ & $(31.3 \%)$ \\
Violence Exposure & $4 \mathrm{a}$ & 3 & $14 \mathrm{a}, \mathrm{b}$ & 14 & $41_{\mathrm{b}}$ \\
Connection & $(12.9 \%)$ & $(14.3 \%)$ & $(35.0 \%)$ & $(23.7 \%)$ & $(20.4 \%)$ \\
High Personal and & $17_{\mathrm{a}, \mathrm{d}}$ & $11_{\mathrm{b}, \mathrm{e}}$ & $5 \mathrm{a}, \mathrm{b}, \mathrm{c}$ & $21 \mathrm{c}, \mathrm{f}$ & $43 \mathrm{~d}, \mathrm{e}, \mathrm{f}$ \\
Empathetic Connection & $(54.8 \%)$ & $(52.4 \%)$ & $(12.5 \%)$ & $(35.6 \%)$ & $(21.4 \%)$ \\
\hline
\end{tabular}

Omnibus $\chi^{2}=39.45(\mathrm{df} 12), \mathrm{p}<.001$

Note - percentages total to 100 within columns. Percentages in cells represent the proportion of respondents within a particular region who are members of each 'motivation for involvement' class. Shared subscripts within a row indicates cells that differ significantly at least $\mathrm{p}<.05$. 


\section{Author biographies:}

Erin A. Casey, Ph.D. is an Associate Professor of Social Work at the University of Washington, Tacoma and Co-Director of the Mobilizing Men for Violence Prevention Research Collaboration. Her research focuses on examining ecological and community-engaged approaches to violence prevention, including engaging men proactively as anti-violence allies, mobilizing change agents within communities, and exploring intersections between violence, masculinities, and sexual risk.

Richard M. Tolman, Ph.D. is the Sheldon D. Rose Collegiate Professor of Social Work at the University of Michigan and Co-Director of the Mobilizing Men for Violence Prevention Research Collaboration. His research focuses on preventing intimate partner violence. His current projects include work on engaging expectant and new fathers to prevent abuse and promote positive partnering and parenting, digital dating abuse, and engaging men as antiviolence allies.

Juliana Carlson, AM, PhD, is an assistant professor at the University of Kansas School of Social Welfare. She received her doctorate from the University of Minnesota, School of Social Work. Her research interests include gender-based violence prevention, intersectional theory, and social welfare policy.

Christopher T. Allen, Ph.D. is an Assistant Professor of Psychology at the University of Massachusetts Lowell. He earned his doctorate in Clinical-Community Psychology at the University of South Carolina. His research is primarily focused on how gender socialization of men and boys has contributed to their underrepresentation in efforts to prevent gender-based violence.

Heather L. Storer, PhD, LMSW is an Assistant Professor at the Tulane School of Social Work. She earned her PhD at the University of Washington School of Social Work. She has worked nationally in the fields of dating and domestic violence prevention and positive youth development. Heather's research agenda focuses on exploring strategies to meaningfully engage youth as partners in the primary prevention of dating violence, sexual assault, and other high-risk behaviors. She is interested in infusing youth empowerment, cumulative adversity and placebased frameworks into the design and implementation of community-level approaches to dating violence prevention and adolescent health promotion. 